\title{
Evidence for Pituitary Regulation of Somatic Growth, Insulin-Like Growth Factors-I and -II, and Their Binding Proteins in the Fetal Rat
}

\author{
JINNA D. KIM, KIRSTI NÄNTÖ-SALONEN, JULIE ROBERTS SZCZEPANKIEWICZ, \\ RON G. ROSENFELD, AND GREGORY F. GLASSCOCK

\begin{abstract}
Department of Neonatology and Pediatric Endocrinology; Stanford Lniversity School of Medicine, Stanford. California 94305 (J.D.K., K.N.-S., R.G.R., G.F.G.J: and Graduate Group of Endocrinolog!: Lniversity of (alifornia, Berkeley; California 94720 /J.R.S./
\end{abstract}

\begin{abstract}
We investigated pituitary regulation of lategestation fetal growth in the spontaneous dwarf rat, a strain with an autosomal recessive mutation (gene symbol dr) in the growth hormone (GH) gene resulting in complete isolated GH deficiency. GH-normal/GH-deficient (Dr/dr) females were crossed with $\mathrm{Dr} / \mathrm{dr}$ or $\mathrm{dr} / \mathrm{dr}$ males, producing both GH-deficient and GH-normal fetuses within the same litter. Pups were killed within $3 \mathrm{~h}$ after birth to approximate the developmental state of a late-gestation fetus. The body weight of GH-deficient fetuses was inhibited by $14 \%$ in comparison to GH-normal animals, but tail length remained unaffected. The brain and lungs were the only organs whose growth appeared to be pituitary-independent. Other organs showed moderate pituitary dependence in proportion to body weight. Serum IGF-I and IGF-II were reduced by $73 \%$ and $52 \%$, respectively, in the absence of GH. The major IGF-binding proteins (IGFBP) were analyzed by Western ligand blot. The predominant 26- to 30kD IGFBP band normally seen in neonatal rat serum was greatly increased in GH-deficient sera, to $250 \%$ of $\mathbf{G H}$ normal sera as measured by densitometry. However, addition of $\alpha$-Hec 1 antibody to IGFBP-2, which has been used to identify IGFBP-2 as the major neonatal IGFBP, resulted in immunoprecipitation of only a small amount of the 26- to $30-\mathrm{kD}$ band from the GH-deficient fetuses, suggesting the presence of an additional IGFBP. Northern analysis of $\mathrm{GH}$-deficient livers did not reveal any visible increase in IGFBP-1, IGFBP-2, or IGFBP-4 mRNA. We conclude that pituitary $\mathrm{GH}$ exerts a modest, but significant, selective effect on fetal body weight and organ growth. Serum levels of both IGF-I and IGF-II, as well as their binding proteins, were shown to be pituitary-GH-dependent in the fetal period. The increase of low-molecularweight binding proteins in the GH-deficient fetus, which we were unable to attribute to IGFBP-1, $-2,-3$, or -4 , may indicate the presence of unique fetal binding protein(s). The spontaneous dwarf rat may be an important model for further investigation of the development of pituitary dependence in fetal growth. (Pediatr Res 33: 144-151, 1993)
\end{abstract}

\section{Abbreviations}

SDS, spontaneous dwarf rat

GH, growth hormone

Received May 8. 1992; accepted September 28. 1992

Correspondence and reprint requests: Dr. G. F. Glasscock. Santa Clara Valley Medical Center, Department of Pediatrics, 750 South Bascom Ave., San Jose. CA 95128-2699.

Supported in part by Grant DK 36054 (R.G.R.) from the NIH: a Developmental and Neonatal Training Grant. NIH (G.F.G.): and a National Science Foundation Graduate Fellowship (J.R.S.)

\author{
IGFBP, insulin-like growth factor binding protein \\ Hx, hypophysectomized \\ Endo $F$, endoglycosidase $F$ \\ Dr, GH-normal (gene symbol) \\ dr, GH-deficient (gene symbol) \\ rGH, rat growth hormone \\ $\mathrm{BP}$, binding protein
}

In mammalian development, the transition from neonate to adult is marked by the rising influence of the pituitary gland in the maintenance of normal somatic growth $(1-5)$. GH, the major promoter of body weight gain and IGF-I and -II expression. is a compelling factor in the ontogeny of pituitary regulation in the postnatal period $(3,5)$. Our previous investigations, which demonstrated a $50 \%$ inhibition of somatic growth in the $\mathrm{Hx}$ neonatal rat after postnatal $\mathrm{d} 6$ that is reversible by $\mathrm{GH}$ and thyroid hormone replacement, have indicated partial pituitary dependence of growth, even at the earliest neonatal stage (4). These findings prompt a closer investigation of the nature of pituitary control of fetal growth.

Fetal somatic growth in most mammalian species has been assumed to be pituitary independent (1). Previous studies have used various methods of pituitary ablation (2), observations of congenital pituitary deficiencies (6), hormonal treatment to mothers or fetuses (7), and in vitro studies (8) for fetal investigation. Jost (2) demonstrated that the growth of fetal rabbits remained unaffected, despite pituitary ablation by decapitation. Studies by Behringer et al. (9), using transgenic mice, have shown that isolated $\mathrm{GH}$ deficiency does not result in observable differences in somatic growth at birth. The birth weights of human infants born with absent pituitaries or isolated $\mathrm{GH}$ deficiency have also been reported to be normal or near normal (3). However, Heggestad and Wells (10) reported a $20 \%$ decrease in somatic growth in the fetal rat after decapitation. which was reversible upon $\mathrm{GH}$ replacement. Definitive analysis of fetal growth has been forestalled by the difficulties in structuring experiments that control for many of the complex factors acknowledged to influence fetal growth, such as uterine size, nutrition, and hormonal (maternal, placental, and fetal) environment. Furthermore, observations from our own laboratory and others' have indicated that fetal trauma from uterine manipulation alone or other invasive techniques inhibits normal growth and decreases serum IGF-I and -II levels (2; Glasscock GF, unpublished data). This makes controlled studies involving fetal or maternal manipulation difficult to interpret.

In an effort to avoid these experimental obstacles. we have used the unique model of the SDR for our study of pituitary 
regulation of fetal growth. The dwarfism results from an autosomal recessive mutation (gene symbol dr) in the GH gene (11). The point mutation causes abnormal splicing and a one-base deletion in the GH mRNA. Consequently, the GH mRNA is present in reduced amounts in the SDR, at 2.6 to $6 \%$ of that in the normal rat $(12,13)$, and the small amounts of GH mRNA produced are nontranslatable, resulting in complete absence of GH protein. No GH was detected in the SDR pituitary by PAGE, immunoblot analysis, or RIA (12, 14-16). GH-containing cells are also absent in the SDR pituitary, as determined by immunocytochemistry. However, it appears to be an isolated deficiency, inasmuch as the presence of prolactin-, ACTH-, TSH-, and $\mathrm{LH}$-producing cells remained unaffected (12). Although the $\mathrm{GH}$ deficiency of the SDR results in body weights than are 30 to $40 \%$ of normal Sprague-Dawley rats at $10 \mathrm{wk}$ of age, SDR males and females are reproductively competent and otherwise healthy (11).

We used the unique characteristics of the SDR model to answer the question: Does Pituitary GH in the late gestation fetal rat contribute to the regulation of fetal growth and the IGF-IGFBP axis? By capitalizing on the genetic transmission of the $\mathrm{GH}$ deficiency, we initiated the appropriate crosses and were able to analyze the growth of a combination of affected GH-deficient and GH-normal fetuses that had developed within the same litter. The advantages of our system include: 1) an isolated GH mutation that maintains normal levels of other pituitary hormones and allows a specific investigation of the role of $\mathrm{GH}$ in fetal growth; 2) complete GH deficiency; 3) reliable categorization of animals based solely on pituitary GH content; 4) a noninvasive method of observing late gestation fetal growth; and 5) a uniform, controlled maternal environment for both dwarf and normal pups. Through this model, we have further examined the nature of fetal growth by illustrating the role of pituitary $\mathrm{GH}$ in the regulation of somatic and organ growth, IGF, and IGFBP.

\section{MATERIALS AND METHODS}

Animals. The strain of SDR was generously provided by Dr. S. Okuma (Morishita Pharmaceutical Co., Ltd., Shiga, Japan). The original $\mathrm{dr} / \mathrm{dr}$ females were crossed with $\mathrm{dr} / \mathrm{dr}$ and $\mathrm{Dr} / \mathrm{dr}$ males to increase our breeding stock for fetal studies. The resulting animals were classified as $\mathrm{dr} / \mathrm{dr}$ GH-deficient or $\mathrm{Dr} / \mathrm{dr} \mathrm{GH}$ normal according to their postnatal growth curves. As demonstrated in previous studies, the dr/dr dwarf rats showed significant inhibition of growth, to less than half the weights of SpragueDawley control rats by postnatal d 30 . However, the somatic growth of $\mathrm{Dr} / \mathrm{dr}$ animals were not different from those of normal Dr/Dr Sprague-Dawley rats of the same postnatal age (Glasscock GF, unpublished data). For the purpose of categorizing the fetal pups, we formed two phenotypic groups based on GH expression: complete GH-deficient and GH-normal. Because their expression of pituitary $\mathrm{GH}$ and their postnatal growth curves were comparable (see below), making Dr/dr and Dr/Dr pups indistinguishable without genetic investigation, both were used in the $\mathrm{GH}$-normal (Dr) group for comparison to the GH-deficient (dr) dwarfs.

To control the maternal size, nutrition, and hormonal environment, only Dr/dr GH-normal females from this stock were used. They were crossed predominantly with $\mathrm{Dr} / \mathrm{dr}$ males, to achieve a combination of GH-deficient and GH-normal pups within the same litter. However, pups from a cross between a $\mathrm{Dr} / \mathrm{dr}$ female and $\mathrm{dr} / \mathrm{dr}$ male were also included in our results because the mean pituitary GH levels, somatic growth, organ weights, and IGF levels of each of the two populations in the litter were not significantly different from those of the same phenotype group from $\mathrm{Dr} / \mathrm{dr} \times \mathrm{Dr} / \mathrm{dr}$ crosses. Thus, paternal factors appeared to have no additional influences other than their direct genetic contribution to GH gene expression. Six litters, each including 10 to 12 pups/litter, were considered in the study for a total of 64 pups.
All rats were housed in 12-h light, 12 -h dark animal facilities, with ambient temperature adjusted to $25^{\circ} \mathrm{C}$. Wayne rodent blok (Premier Lab Diets, Bartonville, IL) and tap water were provided ad libitum. These protocols for animal use were approved by the Department of Laboratory and Animal Medicine, Stanford University.

Growth parameters. Body weight, measured on a digital scale (model S300D, Fisher Scientific, Pittsburgh, PA) to $0.01 \mathrm{~g}$, and tail length, measured from the anus to the tip of the tail, were obtained at the time of birth. Because the tail is composed of vertebral bodies, rat tail length provides an easily measurable index of skeletal growth.

Serum collection and organ weights. Pups were killed by decapitation within $3 \mathrm{~h}$ of delivery. Because the pups were removed immediately after birth, their state primarily represented the condition of a late-gestation fetus. Although there are many changes in hormonal status and a certain amount of extracellular free water loss during the perinatal period $(17,18)$, any such effect was minimized by the promptness of death and is not likely to have greatly altered the birth weights or the other parameters measured. Any perinatal changes would also, presumably, affect both GH-deficient and GH-normal pups to an equal degree. Thus, any data taken immediately after birth are likely to be representative of intrauterine development.

Blood was collected from the cervical stumps, placed on ice, and centrifuged at $12000 \mathrm{rpm}$ for $15 \mathrm{~min}$. Serum was withdrawn and frozen at $-20^{\circ} \mathrm{C}$ for later assay of IGF and IGFBP. Pituitaries were removed and frozen at $-20^{\circ} \mathrm{C}$ for $\mathrm{GH}$ assay. Individual serum samples obtained from GH-deficient and GH-normal pups were pooled after determination of pituitary hormone levels by GH RIA. In each group, two to three individual samples were randomly pooled together to form a volume sufficient for assay.

Individual organs were quickly removed, blotted free of blood, and weighed on a digital scale (model S300D, Fisher Scientific). Livers were frozen in liquid nitrogen at $-70^{\circ} \mathrm{C}$ within $15 \mathrm{~min}$ of decapitation. Due to the difficulty of obtaining accurate (fat-free) weights for ovaries, testes, and adrenals in the newborn pups, these organs were not examined.

Distinguishing genotype. Individual pituitary samples were separately homogenized in $300 \mu \mathrm{L}$ of PBS and $1 \%$ Triton X. Pituitary GH was measured by RIA using ${ }^{125} \mathrm{I}-\mathrm{rGH}$ as the radioligand, a monkey anti-rGH primary antibody, and goat antimonkey secondary antibody. The antiserum (NIDDK-anti-rGHS-5) was obtained from the National Institute of Diabetes and Digestive and Kidney Diseases (NIDDK).

Iodination was performed according to the iodogen method. Five $\mu \mathrm{g}$ of $\mathrm{rGH}$ in PBS were reacted with $0.3 \mathrm{mCi}^{125} \mathrm{I}$. Reaction was stopped after 5 to $8 \mathrm{~min}$ by the addition of $100 \mu \mathrm{L}$ of phosphate buffer $\mathrm{GH}$ and free ${ }^{125} \mathrm{I}$ were fractionated on a $45 \times$ $0.5 \mathrm{~cm}$ column containing Sephadex G-50 in PBS with $0.5 \%$ BSA.

The purpose of the RIA was to categorize the individual newborns as either GH-producing or GH-deficient. The crossreactivity of the antiserum with prolactin was less than $0.16 \%$. The lower limit of sensitivity for GH by RIA was $0.4 \mu \mathrm{g} / \mathrm{L}$ (ng/ $\mathrm{mL}$ ). Pituitary GH levels below this limit were categorized as undetectable and considered indicators of $\mathrm{GH}$-deficient animals. Eighteen of the 64 newborns were included in this category. Other animals with detectable pituitary $\mathrm{GH}$ levels were considered GH-normal. There appeared to be a broad range of pituitary $\mathrm{GH}$ levels represented in the GH-normal group; Dr/Dr and Dr/ $\mathrm{dr}$ animals did not separate into two distinct subpopulations, according to different levels of pituitary GH expression. To avoid any possibilities of errors in grouping resulting from contamination during homogenization or assay or due to RIA sensitivity. we excluded from consideration 13 animals with less than $1 \mu \mathrm{g}$ of pituitary $\mathrm{GH}$ in the sample volume. The remaining 33 animals, all with pituitary $\mathrm{GH}$ greater than this level, were grouped as GH-normal. Because significant sexual dimorphic differences in somatic growth were not shown to be present in the SDR until 
postnatal d 20 (Glasscock GF, unpublished data), both male and female pups were included in both groups.

$R I A$ of $I G F-I$ and $I G F-I I$. Serum samples were chromatographed in $0.25 \mathrm{M}$ formic acid on a $0.9 \times 100 \mathrm{~cm}$ column containing Sephadex G-50 (Pharmacia Fine Chemicals, Piscataway, NJ). The fractions eluting between 50 and $67 \mathrm{~mL}$, which contained $90 \%$ of the IGF activity and no demonstrable IGFBP, were collected in siliconized glass tubes containing $1.0 \mathrm{~mL}$ of $1 \%$ BSA, frozen, and lyophilized. Serum IGF-I was measured by RIA using ${ }^{125}$ I-IGF-I as radioligand and a polyclonal anti-somatomedin-C antibody. This antiserum (UBK487) was a generous gift from the hormone distribution program of the NIDDK and was originally provided by Drs. J. J. Van Wyk and L. E. Underwood (University of North Carolina). Serum IGF-II was measured by RIA using ${ }^{125} \mathrm{I}-\mathrm{IGF}$-II as radioligand and a monoclonal anti-rat-IGF-II antibody (Amano Enzyme Co., Inc., Troy, VA). Lower limits of sensitivity for IGF-I and IGF-II by RIA were $0.013 \mathrm{nmol} / \mathrm{L}(0.1 \mathrm{ng} / \mathrm{mL})$ and $0.067 \mathrm{nmol} / \mathrm{L}(0.5 \mathrm{ng} / \mathrm{mL})$, respectively.

Pure biosynthetic ${ }^{59}$ Thr-IGF-I was purchased from Amgen Biologicals (Thousand Oaks, CA). Recombinant IGF-II was kindly provided by Michele Smith of Eli Lilly Company (Indianapolis, IN). Iodination was performed by a modification of the chloramine-T technique to sp act of $150-250 \mu \mathrm{Ci} / \mu \mathrm{g}$ for each peptide.

IGFBP antibodies. A polyclonal antibody to partially purified human IGFBP-2 and IGFBP-3 secreted by the human endometrial adenocarcinoma cell line HEC 1A $(\alpha-\mathrm{Hec} 1)$ was generated as previously described (19). This polyclonal antibody has been shown to be specific for rat IGFBP-2 in rat serum (20).

Immunoprecipitation. Staphylococcus aureas protein A (Pansorbin, Calbiochem, La Jolla, CA) was washed in $50 \mathrm{mmol} / \mathrm{L}$ Tris $\mathrm{HCl}, \mathrm{pH} \mathrm{7.4}$, and resuspended in Tris buffer at the original volume. Fifty $\mu \mathrm{L}$ of the washed protein A were incubated with 5 $\mu \mathrm{L} \alpha-\mathrm{Hec}$ or $5 \mu \mathrm{L}$ nonimmune rabbit serum on a rotating shelf at $4^{\circ} \mathrm{C}$ overnight. Samples $(20 \mu \mathrm{L}$ of $1: 10$ diluted pooled sera) were then added to the antibody-Staph-A complex and incubated at $4^{\circ} \mathrm{C}$ on a rotating shelf for $3 \mathrm{~h}$. The samples were then microcentrifuged at $15000 \mathrm{rpm}$ for $5 \mathrm{~min}$, and the pellet was washed three times with Tris buffer to remove BP nonspecifically immunoprecipitated by the antibody. Samples were prepared for electrophoresis by the addition of sample buffer (Tris-SDS, glycerol), vortexed, boiled for $5 \mathrm{~min}$, revortexed vigorously, and centrifuged at $15000 \mathrm{rpm}$ for $10 \mathrm{~min}$. The resulting supernatants were electrophoresed, electrotransferred, and ligand blotted with ${ }^{125}$ I-IGF as described below.

Measurement of IGFBP: SDS-PAGE. SDS-PAGE was performed according to the method of Laemmli (21). Twenty $\mu \mathrm{L}$ of $1: 10$ diluted serum were applied per lane to a $4 \%$ stacking gel and electrophoresed through a $10 \%$ polyacrylamide gel. Prestained molecular weight standards (Bethesda Research Laboratories, Gaithersburg, MD) were run in parallel lanes. Some binding protein samples were enzymatically deglycosylated using Endo $F$ (Calbiochem) as previously described (19). Gels were run overnight at $50 \mathrm{~V}$.

Electrotransfer and Western ligand blotting. After electrophoresis, polyacrylamide gels were washed in Towbin buffer $(0.025$ $\mathrm{M}$ Tris-base, $0.192 \mathrm{M}$ glycine, $20 \%$ methanol) for $15 \mathrm{~min}$ to remove SDS before electrotransfer. Proteins were electroblotted onto nitrocellulose $(0.45 \mathrm{mM}$, Schleigher and Schuell, Inc., Keene, $\mathrm{NH}$ ) with a Gelman Biotrans semidry electrophoresis transfer unit (Gelman Sciences, Ann Arbor, MI) using Towbin buffer (TBS) (22). Western ligand blotting was carried out by the method of Hossenlopp et al. (23). Nitrocellulose membranes were washed with TBS $(0.15 \mathrm{M}$ sodium chloride, $0.01 \mathrm{M}$ Tris HCL) containing 3\% Nonidet P-40 (Sigma Chemical Co., St. Louis, MO). Membranes were blocked with TBS containing $1 \%$ BSA (Sigma) for $2 \mathrm{~h}$, followed by TBS containing $0.1 \%$ Tween for $10 \mathrm{~min}$. The membranes were then incubated overnight at $4^{\circ} \mathrm{C}$ with approximately $1.5 \times 10^{6} \mathrm{cpm}$ of an equal amount of
${ }^{125} \mathrm{I}-\mathrm{IGF}-\mathrm{I}$ and -IGF-II in $20 \mathrm{~mL}$ TBS containing $1 \% \mathrm{BSA}$ and $0.1 \%$ Tween. Membranes were washed with TBS and air-dried, and binding proteins were visualized by exposure on Kodak $X$ Omar AR film (Rochester, NY) for $3-7 \mathrm{~d}$ at $-70^{\circ} \mathrm{C}$. Autoradiograms were scanned using a laser densitometer (UltraScan XL; LKB, Bromma, Sweden). The absorbance units $\times \mathrm{mm}$ were measured for each of the major binding proteins.

$R N A$ analysis. Total cellular RNA was isolated from liver tissue from GH-deficient and GH-normal newborn pups. Isolation was performed by a modification of the guanidinium isothiocyanate- $\mathrm{LiCl}$ precipitation method (24). Briefly, approximately $1 \mathrm{~g}$ tissue was dissolved in $1 \mathrm{~mL} \mathrm{GTE}$ buffer $[4.5 \mathrm{~mol} / \mathrm{L}$ guanidinium isothiocyanate, $50 \mathrm{mmol} / \mathrm{L} N$-2-hydroxyethylpi-

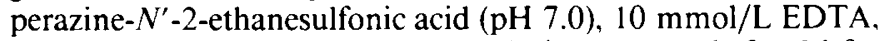
and $5 \%$ 2-mercaptoethanol]. The solution was made $2 \mathrm{mM}$ for $\mathrm{LiCl}$, and RNA was allowed to precipitate for $48 \mathrm{~h}$ at $4^{\circ} \mathrm{C}$. The precipitated RNA was pelleted by centrifugation for $10 \mathrm{~min}$ at $10000 \times g$ at $4^{\circ} \mathrm{C}$, washed twice with cold $3 \mathrm{M} \mathrm{LiCl}$, and finally dissolved in $1 \mathrm{~mL} 10 \mathrm{mM}$ Tris- $\mathrm{HCl}$ ( $\mathrm{pH} \mathrm{7.4),0.05 \%} \mathrm{SDS} \mathrm{(TS).}$ RNA was deproteinized by two phenol-chloroform extractions and a single chloroform extraction. After ethanol precipitation, RNA was dissolved in TS, quantified spectrophotometrically, and stored at $-70^{\circ} \mathrm{C}$. RNA samples were size-fractionated in a $1.2 \%$ agarose-formaldehyde gel, transferred onto nitrocellulose, and hybridized with rat cDNA for IGFBP-2, IGFBP-1, and IGFBP-4 according to the method of Wahl et al. (25). The blot was washed twice for $10 \mathrm{~min}$ at $55^{\circ} \mathrm{C}$ in $0.2 \times \mathrm{SSC}$ (sodium chloride, sodium citrate) $-0.5 \%$ SDS, air dried, and exposed to XAR film (Eastman Kodak, Rochester, NY) at $-70^{\circ} \mathrm{C}$ with an intensifying screen (Dupont, Wilmington, DE) for $1-4 \mathrm{~d}$. The cDNA probe for rat IGFBP-2 was a 1295-bp EcoRI restriction fragment of the 1500-bp cDNA isolated from a rat liver cDNA library and contained the whole coding region. The probe for human IGFBP-1, cross-reacting with rat IGFBP-1, was a 367-bp Pst $\mathrm{I}$-Bam HI coding region fragment of the HepG2 IGFBP cDNA (26). The probe for human IGFBP-4 was a 440-bp SmaI-restriction fragment of the $1.2-\mathrm{kb}$ cDNA isolated from a human osteosarcoma cell gene library (27). The probes were generously provided by Drs. J. Schwander (Basel, Switzerland), D. Powell (Houston, TX), and M. Mohan (Loma Linda, CA), respectively, and were labeled with ${ }^{32} \mathrm{P}-\mathrm{dCTP}$ (Amersham Co., Arlington Heights, IL) by random priming using a commercial kit (Pharmacia, Uppsala, Sweden).

Statistical analysis. Student's $t$ test was used for determination of statistically significant differences between the two groups for body weight, tail length, organ weights and organ weight ratios, serum IGF levels, and absorbance units for IGFBP.

\section{RESULTS}

Fetal somatic growth. As illustrated in Figure $1 A$, body weight was modestly but significantly decreased in GH-deficient pups at birth $(\mathrm{d} 0)$. The mean birth weight of $\mathrm{GH}$-deficient fetuses, $5.0 \pm 0.1 \mathrm{~g}$ (mean $\pm \mathrm{SEM}$ ), was $14 \%$ less than the GH-normal pups at $5.8 \pm 0.1 \mathrm{~g}(p<0.0001)$. However, tail length showed no pituitary dependency (Fig. $1 B$ ). Mean tail length of $\mathrm{GH}$ deficient pups was $16.8 \pm 0.3 \mathrm{~mm}$ as compared with $16.9 \pm 0.2$ $\mathrm{mm}$ in GH-normal pups. At birth, the tail length of GH-deficient pups was not different from that of GH-normal pups, thereby demonstrating the significant effect of $\mathrm{GH}$ on fetal body weight. but not skeletal growth.

Fetal organ weights. Table I compares organ weight data between GH-normal and GH-deficient fetuses at birth. Among the organs listed, there appear to be three patterns of growth evident from organ weights at birth. The growth of the brain was preserved, regardless of its hormonal environment; brain weight in GH-deficient pups was $97 \%$ of the $\mathrm{GH}$-normal group. The weight of the lungs was also comparable in both groups, increasing (but not significantly) in GH-deficient fetuses to $114 \%$ of control values. To further demonstrate the selective effects of 

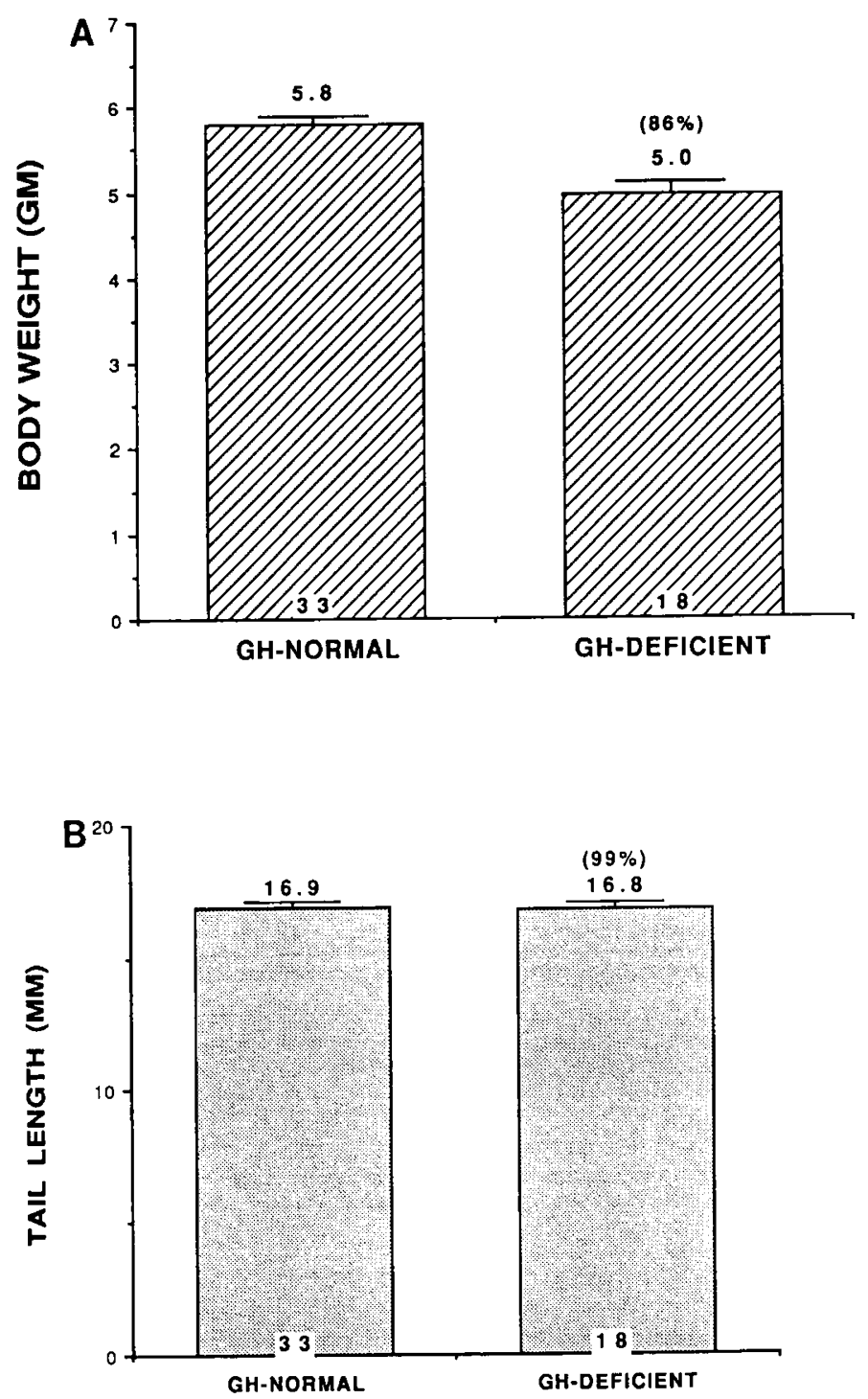

Fig. 1. The effects of GH deficiency on fetal somatic growth. Body weight $(A)$ and tail length $(B)$ were graphed according to phenotype in newborn (postnatal d 0) SDR. The phenotype group is indicated below each column. The number of animals measured $(n)$ is indicated at the base of each column. The values above the error bars represent means. $t$ test compares GH-normal vs GH-deficient and shows them to be significantly different $(p<0.0001)$ for body weight and not statistically different for tail length.

fetal pituitary GH on organ growth, the absolute weights were corrected for their corresponding body weights and presented as an organ weight ratio. This showed the brain and lungs of $\mathrm{GH}$ deficient pups to grow in excess of body weight, at 115 and $129 \%$ of GH-normal control values, but only the brain weight ratios were significantly increased $(p<0.0001)$. The brain, therefore, remains pituitary-independent during the fetal period, and its growth persists despite the inhibition of body weight growth shown in the GH-deficient animals. This pattern of growth observed in the brain and, to a lesser extent, in the lung is continued in the neonatal period (4).

In contrast, growth of the heart, liver, and kidneys was clearly inhibited. Their weights in GH-deficient fetuses were $81-88 \%$ of GH-normal controls and were significantly different $(p<0.01$ for kidneys, $p<0.001$ for heart, and $p<0.0001$ for liver). Based on organ weight ratios, these organs were also shown to grow in proportion to body weight (Table 1). Liver growth was only slightly decreased in comparison to body weight in GH-deficient fetuses, at $95 \%$ of the GH-normal ratio. Thus, it appears that the growth of the heart, kidneys, and liver in the late gestation fetus is pituitary-dependent and proportional to overall somatic growth. The moderate pituitary dependence of the heart, liver, and kidney also continues and is amplified during the neonatal stage (4).

Finally, the inhibition of splenic weight was greatest, but the $43 \%$ decrease in absolute weight and $32 \%$ decrease in splenic weight ratio in the $\mathrm{GH}$-deficient pups did not reach statistical significance because of relatively large individual organ weight variability. The inhibitory effect shown here in the spleen has been shown to be more dramatic in the neonatal period (4).

Fetal serum IGF levels. In Figure $2 A$ and $B$, serum IGF levels are plotted for GH-normal and GH-deficient fetuses. Serum IGFI levels in GH-deficient pups of $2.5 \pm 0.1 \mathrm{nmol} / \mathrm{L}(19 \pm 1 \mathrm{ng} /$ $\mathrm{mL}$ ) (mean $\pm \mathrm{SEM}$ ) were dramatically lower in comparison to those of GH-normal pups, measuring only $27 \%$ of the GHnormal group $(p<0.0001)$. Fetal IGF-II levels were also greatly affected by the absence of pituitary GH. Figure $2 B$ displays a drop of $52 \%$ in the $\mathrm{GH}$-deficient group to $12.5 \pm 0.8 \mathrm{nmol} / \mathrm{L}$ $(93 \pm 6 \mathrm{ng} / \mathrm{mL})$. The attenuated expression of IGF-I and -II in the GH-deficient pups demonstrates the partial GH-dependent nature of IGF in the fetus.

Western ligand blots of serum IGFBP. Figure $3 A$ shows the results of a Western ligand blot performed on pooled $\mathrm{GH}$ deficient (dr) and GH-normal (Dr) sera. In addition, pooled sera from newborn controls $(n b)$ are shown (lane 13$)$. Only one major BP band, at approximately $26-30 \mathrm{kD}$, was visualized on the blot. Previous work in neonatal rats $(28,29)$ has shown the band to be composed of IGFBP-1, nonglycosylated or proteolyzed IGFBP-3, and, as a major contributor, IGFBP-2. The level of IGFBP expression in the newborn control appears comparable to those of the GH-normal (Dr) pools (lanes 7-12). Densitometry was performed to determine relative amounts of the BP in GHdeficient and GH-normal groups, and results are shown in Figure $3 C$.

When compared with the GH-normal sera, the absorbancy of the 26- to $30-\mathrm{kD}$ BP complex in GH-deficient sera showed a dramatic increase to $250 \%$ of $\mathrm{GH}$-normal values $(p<0.005)$. To more closely examine the nature of the increase in the 26- to $30-\mathrm{kD}$ BP band, a comparison of the BP in both groups after immunoprecipitation with $\alpha$-Hec- 1 antibody was conducted (Fig. 3B). This antibody specifically immunoprecipitates rat IGFBP-2, normally the major neonatal rat serum IGFBP (19, 29). The first two lanes are Western ligand blots of GH-deficient and GH-normal sera, respectively. Note that the $26-$ to $30-\mathrm{kD}$ band in GH-deficient serum is more intense than in GH-normal serum, as previously described. The immunoprecipitation of GH-deficient sera (lane 3) resulted in a minor $26-$ to $30-\mathrm{kD}$ band, compared with its relative abundance in the ligand blot (lane 1). Furthermore, the 26- to $30-\mathrm{kD}$ band from the immunoprecipitated GH-deficient sera was considerably less prominent than the same band in the immunoprecipitated GH-normal sera (lane 4). This indicates a decreased relative expression of immunoreactive IGFBP-2 in the $26-$ to $30-\mathrm{kD}$ region in the sera of $\mathrm{GH}$-deficient pups.

Deglycosylation with Endo F of IGFBP in GH-deficient and GH-normal sera was also performed. The results showed no visible differences between the $26-$ to $30-\mathrm{kD}$ bands in the lanes treated with Endo $F$ and the untreated lanes, indicating the absence of $\mathrm{N}$-linked glucosamine groups associated with the IGFBP in that complex (data not shown). These findings imply that the 26- to $30-\mathrm{kD}$ band does not contain significant amounts of glycosylated IGFBP-4 or IGFBP-3 fragments (28).

Therefore, the absence of GH in the SDR fetuses was associated with an increased quantity of binding proteins in the 26- to $30-\mathrm{kD}$ band, the same region as IGFBP-2. However, based on immunoprecipitation with $\alpha$-Hec 1 and studies with Endo $\mathrm{F}$ digestion, we conclude that the increased binding protein is not IGFBP-2, glycosylated IGFBP-4, or IGFBP-3 fragments.

Northern analysis of IGFBP-1, IGFBP-2, and IGFBP-4 $m R N A$. Figure 4 shows the results of Northern analysis on liver 
Table 1. Summary of organ weights and organ weight ratios for SDR GH-normal and GH-deficient newhorn pup**

\begin{tabular}{lccccc}
\hline & \multicolumn{2}{c}{ Organ wt $(\mathrm{g})$} & & \multicolumn{2}{c}{ Organ wt ratio ${ }^{\dagger}$} \\
\cline { 2 - 3 } \cline { 5 - 6 } Organ & GH-normal & GH-deficient & & GH-normal & GH-deficient \\
\hline Brain & $0.227 \pm 0.030$ & $0.221 \pm 0.031(97)$ & & $0.039 \pm 0.002$ & $0.045 \pm 0.007(115) \ddagger$ \\
Lungs & $0.095 \pm 0.030$ & $0.108 \pm 0.070(114)$ & & $0.017 \pm 0.005$ & $0.022 \pm 0.013(129)$ \\
Heart & $0.036 \pm 0.006$ & $0.031 \pm 0.006(86) \S$ & & $0.006 \pm 0.001$ & $0.006 \pm 0.001(100)$ \\
Liver & $0.315 \pm 0.034$ & $0.255 \pm 0.060(81) \ddagger$ & & $0.055 \pm 0.008$ & $0.052 \pm 0.012(95)$ \\
Kidneys & $0.056 \pm 0.010$ & $0.049 \pm 0.007(88) \|$ & & $0.01 \pm 0.001$ & $0.01 \pm 0.001(100)$ \\
Spleen & $0.014 \pm 0.016$ & $0.008 \pm 0.003(57)$ & $0.0024 \pm 0.003$ & $0.0017 \pm 0.005(68)$ \\
\hline
\end{tabular}

* Summary of organ wt and organ wt ratios for SDR at birth. Phenotype is indicated above each column and values represent mean \pm SD. The values in parentheses represent the GH-deficient organ wt or ratios as a percentage of GH-normal values. The number of organs measured (both lobes of lungs and both kidneys were considered together as one organ) were $n=33$ for GH-normal and $n=18$ for GH-deficient rats.

+ Organ $w$ t ratio $=$ organ wt/body wt.

$\ddagger p<0.0001$.

$\$ p<0.001$.

$\| p<0.01$.
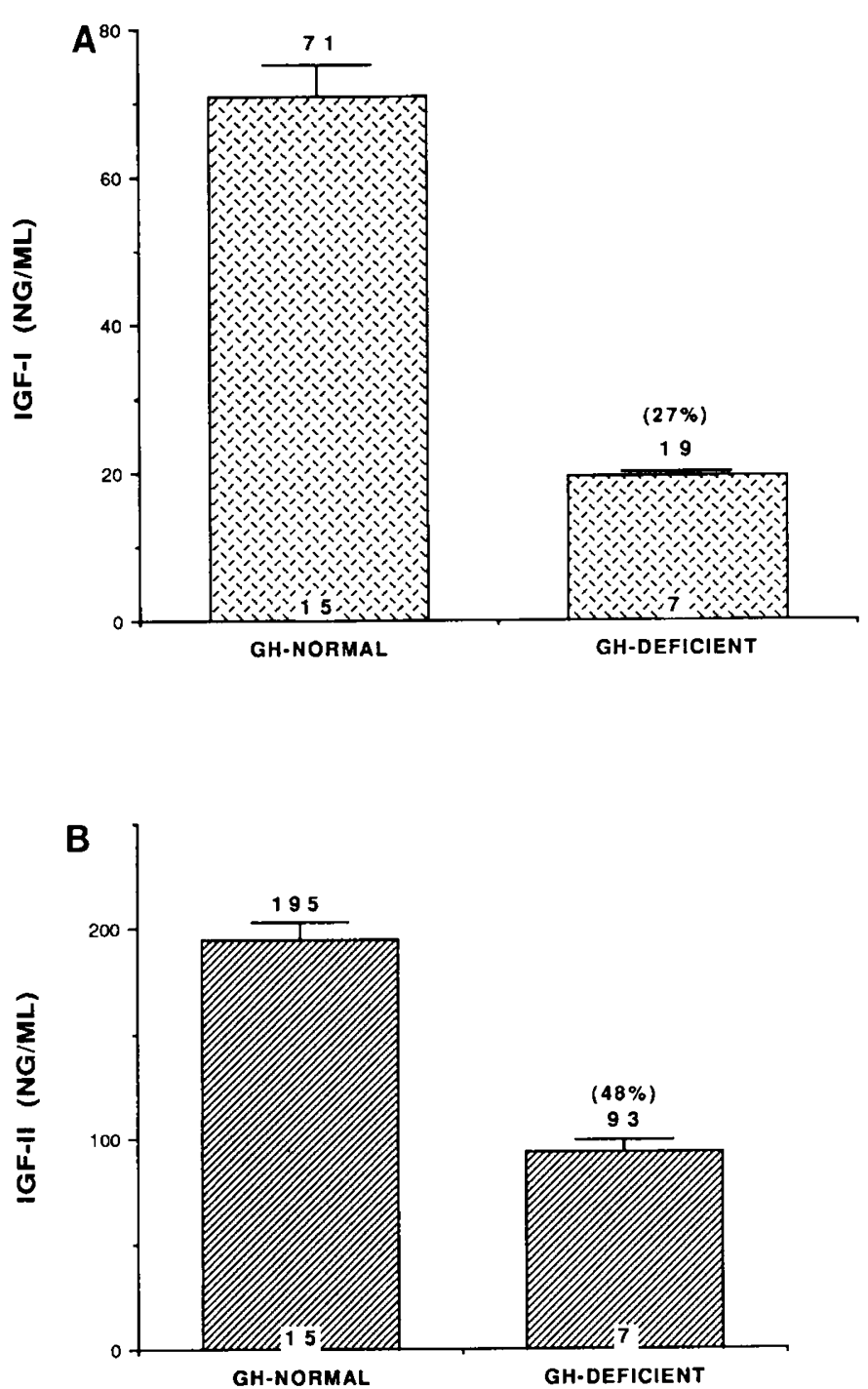

Fig. 2. Effects of GH-deficiency on serum IGF levels in fetal SDR. Phenotype indicated below each column for serum IGF-I $(A)$ and serum IGF-II $(B)$. Each value represents mean \pm SEM. To convert to SI units of $\mathrm{nmol} / \mathrm{L}$. conversion factors of 0.131 and 0.134 may be multiplied with IGF-I and IGF-II values, respectively. Sera from fetuses were pooled according to phenotype. For GH-normal pups, 33 samples were combined into 15 pools. Seven pools of 18 serum samples were collected for GH-deficient pups. $t$ test shows $p<0.0001$ for both serum IGF-I and -II in GH-normal vs GH-deficient newborns. tissue taken from GH-normal and GH-deficient pups at birth, which were probed for IGFBP-1, IGFBP-2, and IGFBP-4 mRNA. The livers of three GH-deficient and five GH-normal fetuses were randomly selected, and the tissues were evaluated for these individual animals. The levels of IGFBP-2 mRNA were comparable in the GH-deficient and the GH-normal fetuses. Thus, the increase of serum IGFBP in GH-deficient sera is not accompanied by an increase in the mRNA of the major IGFBP of the fetal period. This is consistent with the immunoprecipitation results, which indicate that the higher intensity of the 26to $30-\mathrm{kD}$ region in the $\mathrm{GH}$-deficient group is not likely to be due to increased expression of IGFBP-2. Similar results of Northern analysis when probing for IGFBP-1 and IGFBP-4 mRNA (Fig. 4) make augmented IGFBP-1 and IGFBP-4 gene transcription improbable sources for the binding protein increase in the $\mathrm{GH}$ deficient animals. Hybridization with IGFBP-3 probe (data not shown) revealed a slight decrease in IGFBP-3 mRNA expression in GH-deficient liver tissue, as compared with GH-normal, thus also making it an unlikely contributor to the increase. Other alternatives such as decreased degradation of IGFBP-1, -3 , or -4 as well as increased degradation of IGFBP-2 may also account for the binding protein increase.

\section{DISCUSSION}

Our results demonstrate the incipient pituitary regulation of somatic growth during the late gestation fetal stage of mammalian development in the rat. Previous studies have supported the pituitary-independent nature of fetal growth. Human anencephalics have been reported to have normal birth weights. Fetal decapitation in several species, including the rat and rabbit, has failed to affect somatic growth (1). In contrast, the juvenile period is characterized by a near complete pituitary dependence of growth; body weight and skeletal growth were inhibited by 80 and $85 \%$ in $\mathrm{Hx}$ juvenile rats (5). Our prior studies, investigating the transition in pituitary regulation from fetus to adult, have documented a partial pituitary dependence of somatic growth, serum IGF, and IGFBP in $\mathrm{Hx}$ neonatal rats as early as postnatal d 6 (3-5). Thus, our previous data have presented a clear pattern of pituitary dependence in the rat: the influence of pituitary hormones in maintaining normal somatic growth and the IGFIGFBP axis is notable early in the neonatal period and becomes more pronounced with increasing postnatal age.

Using the model of the GH-deficient SDR, we have extended the scope of our investigation to an even earlier stage of development, while also avoiding the extensive fetal trauma incurred by previous invasive techniques. Because the pituitary content of $\mathrm{GH}$ is only detectable beginning at d 19 of gestation (30), we could speculate about the nature of the onset of $\mathrm{GH}$ contribution to growth within the limited time frame of late gestation.

From our data, we have formed a more distinct view of the 
$\begin{array}{cccccccccccccc}M r \times 10^{-3} & 1 & 2 & 3 & 4 & 5 & 6 & 7 & 8 & 9 & 10 & 11 & 12 & 13\end{array}$

A

42.7 .

27.4

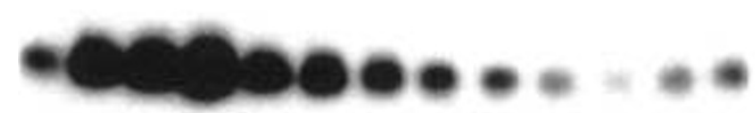

IGFBP-I

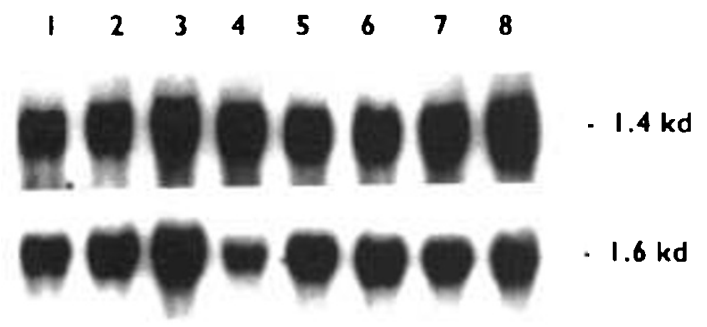

IGFBP-4

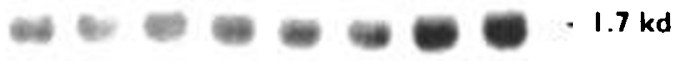

18.1

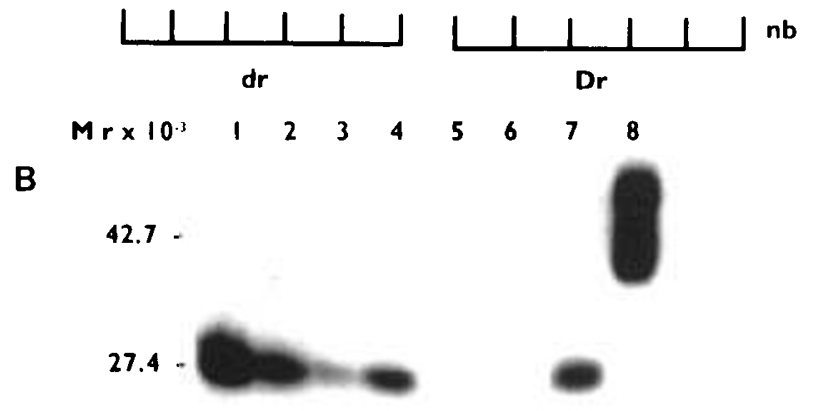

$18.1-$
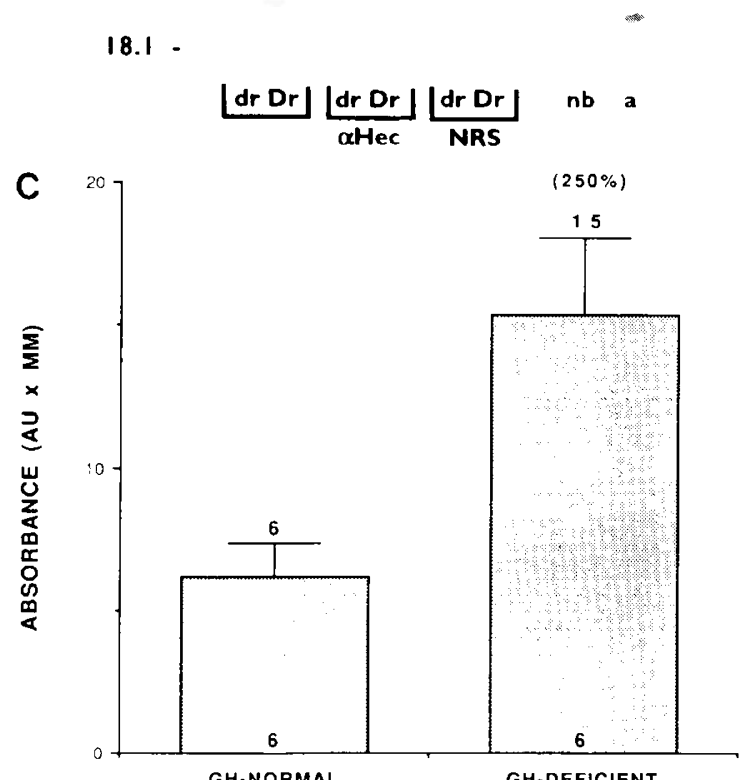

Fig. 3. Western ligand blots of IGFBP from fetal SDR. A, Autoradiograph of a Western ligand blot of fetal rat serum IGFBP from Dr and $\mathrm{dr}$ pups. Each lane on the gel represents pooled sera from two to three pups. Lanes 1-6 are from dr pups, and lanes $7-12$ are from Dr pups. Lane $13(n b)$ includes the pooled sera from newborn control pups. Molecular mass markers in $\mathrm{kD}\left(\mathrm{M}_{\mathrm{r}} \times 10^{-3}\right)$ are shown on the left. $B$, Autoradiograph of Western ligand blot of immunoprecipitation with $\alpha$ Hec 1 antibody of pooled sera from $\mathrm{dr}$ and Dr pups. The first two lanes show untreated samples, and lanes 3 and 4 show the respective samples immunoprecipitated with $\alpha-\mathrm{Hec}$ antibody. Lanes 5 and 6 represent the samples immunoprecipitated with nonimmune rabbit serum $(N R S)$. Lane's 7 and 8 include pools of untreated newborn and adult rat sera, respectively. Molecular mass markers in $\mathrm{kD}$ are shown on the left. $C$, Densitometric scan of the autoradiograph shown in $A$. Mean \pm SEM of absorbance units (AU) $\times \mathrm{mm}$ for the 26- to $30-\mathrm{kD}$ BP region are shown for $\mathrm{GH}$-normal $(n=6)$ and $\mathrm{GH}$-deficient $(n=6)$ pups. $t$ test shows a significant increase in absorption for $\mathrm{GH}$-deficient pups in comparison to $\mathrm{GH}$ normal pups $(p<0.005)$.
185 subunit

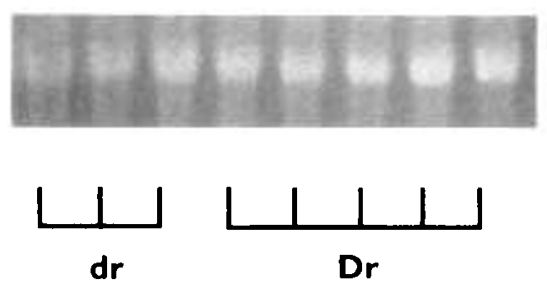

Fig. 4. Northern blot analysis of liver rat IGFBP-2, IGFBP-1, and IGFBP-4 mRNA from dr (lanes 1-3) and Dr (lanes 4-8) newborns. Molecular mass marker in $\mathrm{kD}$ are shown on the right. Dr liver mRNA is displayed in lanes $4-8$. The blot was sequentially hybridized with cDNA probes for IGFBP-2. IGFBP-1, and IGFBP-4. The ethidium were photographed under UV light to demonstrate equal RNA loads in the different lanes.

role of the pituitary in early mammalian development: the $\mathrm{GH}$ regulation of somatic growth is clearly present in the late-gestation fetus, but its influence is not as extensive as in the postnatal period. We have shown previously in the $\mathrm{Hx}$ neonatal rat that, by postnatal $\mathrm{d} 25$, body weight and tail length are inhibited by 50 and $32 \%$, respectively, compared with sham control values $(4,5)$. Growth in $\mathrm{Hx}$ juveniles nearly ceased, showing an inhibition in body weight and tail length of 80 and $85 \%$, respectively (5). In contrast, our fetal study demonstrated that body weight was inhibited by $14 \%$ and tail length remained unaffected in $\mathrm{GH}$-deficient newborns. This illustrates the modest effect of $\mathrm{GH}$ deficiency during the fetal stage. The slight inhibition of body weight and absence of effect on tail length confirm the role of GH demonstrated in our neonatal studies, which shows a predominant effect of $\mathrm{GH}$ over soft tissue growth, rather than skeletal growth (5).

The responses of individual organs in the SDR fetuses also As in the neonate, the brain and lungs were the only organs whose growth remained pituitary-independent. The brain's preservation, despite $\mathrm{GH}$ deficiency, may be a physiologic protective mechanism, allowing for continued neurologic function and development, despite the stress of suboptimal hormonal and metabolic conditions. Pituitary-independent growth may result from local (autocrine/paracrine) actions of IGF not reflected in serum IGF levels (31) or from the generation of other growth factors (i.e. nerve growth factor, fibroblast growth factor, and epidermal growth factor).

The majority of fetal organs examined exhibited moderate pituitary dependency. The kidneys, heart, and liver proved to be significantly affected by the absence of pituitary $\mathrm{GH}$. However, although their growth was inhibited, the decrease in organ weight was proportional to changes in body weight. This finding is consistent with the moderate organ responses of $\mathrm{Hx}$ neonates (4).

The limited inhibition of somatic growth and organ weights despite complete $\mathrm{GH}$ deficiency reflects, at least in part, the effects on IGF and IGFBP. The anabolic actions of GH have been presumed to be mediated by IGF, which are under pituitary regulation in the postnatal period. In reverse of the postnatal bromide-stained $18 \mathrm{~S}$ ribosomal RNA bands on the nitrocellulose filter revealed three important patterns of growth regulated by $\mathrm{GH}$. 
situation, serum IGF-II concentrations are nearly three times greater than the level of IGF-I in the fetus. Both IGF-I and -II showed significant decreases in the GH-deficient fetuses compared with the GH-normal fetuses, demonstrating a role for $\mathrm{GH}$ in the regulation of fetal IGF. Serum IGF-I in the GH-deficient group, at $27 \%$ of GH-normal controls, showed a greater pituitary dependency than IGF-II, which, despite a $52 \%$ decrease, remained at levels higher than in the neonate after $\mathrm{Hx}(5)$. The pituitary dependence of IGF-I remains relatively constant in older animals, as demonstrated by its $75 \%$ decrease in $\mathrm{Hx}$ neonates (5). However, IGF-II shows an increasing pituitary dependence with age, reflected in its $80 \%$ inhibition in the $\mathrm{Hx}$ neonate (5).

In the fetus, serum IGF-II levels are high (32) even before the presence of $\mathrm{GH}$ is detected in the pituitary at $\mathrm{d} 19$ of gestation (30). Evidence in prior studies has indirectly supported the role of IGF-II as the major fetal growth regulator (33). Through selective targeting of the IGF-II gene in mice, DeChiara et al. (34) have shown that IGF-II is an important regulator of approximately $40 \%$ of early (by embryonic d 16) prenatal growth but is ineffective in the postnatal period. This indicates the prominent effect of IGF-II early in fetal life, independent of the pituitary. Furthermore, our findings that continuous infusion of IGF-II fails to increase somatic growth in the $\mathrm{Hx}$ neonatal rat supports its exclusive role as a somatic growth factor prenatally in the rat (31).

In our previous studies, we have shown that the gradual decline from elevated levels of IGF-II in the early postnatal period is accelerated by $\mathrm{Hx}$ at $\mathrm{d} 6(4,5)$. $\mathrm{GH}$ replacement in neonates returned IGF-II to sham values, thereby demonstrating its importance in regulating serum IGF-II levels in the immediate postnatal period $(4,5)$. Although serum IGF-II is inhibited by more than $50 \%$ in $\mathrm{GH}$-deficient fetuses, its continued expression reflects a partial independence of the pituitary and may account for the relatively modest effect of complete GH deficiency on somatic growth in the neonatal rat. The near normal growth of the $\mathrm{GH}$-deficient fetuses, like the persistent $40 \%$ growth rate in $\mathrm{Hx}$ neonates, may result from higher tissue levels of both IGF, allowing for increased autocrine/paracrine growth-promoting activity not reflected in serum levels. Also, fetal tissue may have enhanced sensitivity to lower IGF levels, an increased concentration of IGF receptors, or IGF-sensitive cell populations [i.e. chondrocytes on growth plates $(35,36)]$.

Another contributing factor to the partial preservation of somatic growth in GH-deficient fetuses may involve their increased expression of fetal binding proteins. In the sera from the GH-deficient group, the 26- to $30-\mathrm{kD}$ binding protein complex showed a marked increase, compared with GH-normal rats, as measured by Western ligand blot. The IGFBP may alter IGF degradation and clearance and maximize the anabolic effects of IGF, resulting in more favorable use of limited calories, which is necessary in preserving somatic growth and organs such as the brain. Although the understanding of IGFBP function in whole animals is not yet complete, studies have shown that IGFBP may facilitate the peripheral actions of IGF at target tissues (37-39). Increased IGFBP function may thus help to explain the continued maintenance of organs and somatic growth despite GH deficiency.

However, the results of immunoprecipitation with $\alpha$-Hec 1 antibody, deglycosylation with Endo F, and Northern analysis climinate the major neonatal binding protein. IGFBP-2, or IGFBP-1, IGFBP-3, or IGFBP-4 as likely sources of the increased intensity of the 26 - to $30-\mathrm{kD}$ band in GH-deficient sera. This implies the presence of specific binding protein(s) operative primarily in the perinatal period. Further investigation is needed into the nature and function of these fetal/neonatal binding proteins. The expression of IGFBP-5 $\mathrm{mRNA}$ has been shown to be very low or absent in the liver (40) and, therefore, could not be explored in our studies. For future studies, we will investigate the effects of GH deficiency on IGFBP-5 expression in other fetal tissues such as the kidney, heart, and lung (40).

The production by the human placenta of $\mathrm{GH}$ variants, which have been found to stimulate growth in transgenic mice, may present difficulties in extrapolating from our studies to the human (41). Although the hGH variant is found to be selectively secreted into the maternal circulation (42), there may be a low but sufficient level of the variant directed into the fetal bloodstream to prevent $\mathrm{GH}$ deficiency in the fetus. In the rat, however, it is not yet clear whether such placental variants exist. Although some portion of rat fetal growth may possibly be attributed to such a cause, the primary contribution of the GH variant would more likely be to maternal metabolism, as in humans.

The data presented here offer insight into the complex role of the pituitary during fetal development in the rat. Through the isolated GH mutation in the SDR, we have been able to focus specifically on GH function in the late gestation fetus. Many of the effects of $\mathrm{GH}$ in the late gestation fetus on body weight. organ growth, IGF, and IGFBP are consistent with our expectations from previous studies in neonatal, juvenile, and adult rats. We have shown the pituitary control of somatic growth in the fetus to be modest but significant. As in the neonate, $\mathrm{GH}$ in the fetus is primarily a regulator of soft-tissue growth and not skeletal growth. Three patterns of organ response were observed, with the brain and lungs being the only organs whose growth remained completely pituitary-independent. In addition, GH control over both IGF was clearly established by the end of the prenatal period. The marked increase in the $26-$ to $30-\mathrm{kD}$ BP in GHdeficient rats indicates a role for GH in IGFBP regulation in the fetus, which may, in turn, regulate IGF action.

Acknowledgments. The authors thank Katy Young and Anthony N. Hein for their technical assistance.

\section{REFERENCES}

1. Cooke PS, Nicoll CS 1983 Hormonal control of fetal growth. The Physiologist 26:317-323

2. Jost A 1979 Fetal hormones and fetal growth. In: Keller P (ed) Contributions to Gynecologic and Obstetric Investigation. Skarger Press. Basel, pp 1-20

3. Glasscock GF, Nicoll CS 1981 Hormonal control of growth in the infant rat. Endocrinology 109:176-184

4. Glasscock GF, Gelber SE, Larmson G, McGee-Tekula R, Rosenfeld RG 1990 Pituitary control of growth in the neonatal rat: effects of neonatal hypophysectomy on somatic and organ growth, serum insulin-like growth factor-1 (IGF-I) and -II levels and expression of IGF-binding proteins. Endocrinolog: 127:1792-1803

5. Glasscock GF, Gin KK-L, Kim JD, Hintz RL, Rosenfeld RG 1991 Ontogeny of pituitary regulation of growth in the developing rat: comparison of effects of hypophysectomy and hormone replacement on somatic and organ growth. serum insulin-like growth factor-I (IGF-I) and IGF-II levels, and expression of IGF-binding protein levels in the neonatal and juvenile rat. Endocrinology 128:1036-1047

6. Reid J 1970 Congenital absence of the pituitary gland. J Pediatr 56:658-666

7. Picon L 1967 Effect of insulin on growth and biochemical composition of the rat fetus. Endocrinology 81:1419-1421

8. Ashton I, Francis M 1978 Response of chondrocytes isolated from human foetal cartilage to plasma somatomedin activity. J Endocrinol 76:473-477

9. Behringer RR. Lewin TM, Quaife CJ. Palmiter RD, Brinster RL, D'Ercole AJ 1990 Expression of insulin-like growth factor I stimulates normal somatic growth in growth hormone deficient transgenic mice. Endocrinology 127:1033-1040

10. Heggestad CB, Wells LJ 1965 Experiments on the contribution of somatotrophin to prenatal growth in the rat. Acta Anat (Basel) 60:348-361

11. Okuma S, Kawashima S 1980 Spontaneous dwarf rat. Exp Anim 29:301-308

12. Nogami H. Takeuchi T, Suzuki K. Okuma S. Ishikawa H 1989 Studies on prolactin and growth hormone gene expression in the pituitary gland of spontaneous dwarf rats. Endocrinology 125:964-970

13. Takeuchi T. Suzuki K. Sakurai S. Nogami H. Okuma S. Ishikawa H 1990 Molecular mechanism of growth hormone $(\mathrm{GH})$ deficiency in the spontaneous dwarf rat: detection of abnormal splicing of GH messenger ribonucleic acid by the polymerase chain reaction. Endocrinology 126:31-38

14. Okuma S 1984 Study of growth hormone in spontaneous dwarf rat. Folia Endocrinol 60:1005-1014

15. Nogami H, Suzuki K, Matsui K, Okuma S, Ishikawa H 1989 Electronmicroscopic study on the anterior pituitary gland of spontaneous dwarf rats. Cell Tissue Res 258:477-482

16. Sakuma S, Maekawa K. Ishikawa H 1989 Immunohistochemical studies on the somatostatin- and growth hormone-releasing factor (GRF)-neurons in 


\section{ISOLATED GH DEFICIENCY IN FETAL RAT}

the hypothalamus of the novel dwarf rat: the spontaneous dwarf rat (dr). Brain Res 493:402-406

17. Haymond MW, Pagliera AS, Bier DM 1989 Endocrine and metabolic aspects of fuel homeostasis in the fetus and neonate. In: De Groot $\mathrm{LJ}$ (ed) Endocrinology. Harcourt Brace Jovanovich, Inc., Philadelphia, pp 2215-2241

18. Fisher DA 1992 Endocrinology of Fetal Development. In: Wilson JD, Foster DW (eds) Williams Textbook of Endocrinology. Harcourt Brace Jovanovich, Inc., Philadelphia, pp 1049-1077

19. Lamson G, Oh Y. Pham H. Guidice LG, Rosenfeld RG 1989 Expression of two insulin-like growth factor binding proteins in a human endometrial cancer cell line: structural, immunological, and genetic characterization. J Clin Endocrinol Metab 69:852-859

20. Lamson G. Pham H, Oh Y, Ocrant I, Schwander J, Rosenfeld RG 1989 Expression of BRL-3A(rBP-30) in the rat central nervous system. Endocrinology 123:1100-1103

21. Laemmli $V 1970$ Cleavage of structural proteins during the assembly of the head of the bacteriophage T4. Nature 227:680-685

22. Towbin H. Stachelin T. Gordon J 1979 Electrophoretic transfer of proteins from polyacrylamide gels to nitroceltulose sheets: procedure and some applications. Proc Natl Acad Sci USA 76:4350-4354

23. Hossenlopp P. Seurin D. Segovia-Quinson B. Hardonin S, Binoux M 1986 Analysis of serum insulin-like growth factor binding proteins and competitive binding studies. Anal Biochem 154:138-143

24. Cathala G, Savouret J-F. Mendez B. West DL, Karin M, Martial JA, Baxter JD 1983 A method of isolation of intact, translationally active ribonucleic acid. DNA 2:329-335

25. Wahl GM, Stern M, Stark GR 1979 Efficient transfer of large DNA fragments from agarose gels to diazobenzyloxymethyl-paper and rapid hybridization using dextran sulfate. Proc Natl Acad Sci USA 76:3683-3687

26. Lee Y-L. Hintz RL, James PM. Lee PDK, Shively KJE, Powell DR 1988 Insulin-like growth factor (IGF) binding protein complementary deoxyribonucleic acid from human Hep $\mathrm{G} 2$ hepatoma cells: predicted protein sequence suggests an IGF binding domain different from those of the IGF-I and IGFIl receptors. Mol Endocrinol 2:404-411

27. LaTour D, Mohan S, Linkhart TA, Baylink DJ, Strong DD 1990 Inhibitory insulin-like growth factor binding protein: cloning, complete sequence and physiological regulation. Mol Endocrinol 4:1806-1814

28. Yang YW-H, Wang J-F, Orlowski CC, Nissley SP, Rechler MM 1989 Structure specificity and regulation of the insulin-like growth factor binding protein in adult rat serum. Endocrinology 125:1540-1555

29. Donovan SM, Oh Y, Pham H, Rosenfeld RG 1989 Ontogeny of serum insulinlike growth factor binding proteins in the rat. Endocrinology 125:2621-2627
30. Rieutort M 1973 Pituitary content and plasma levels of growth hormone in foetal and weanling rats. J Endocrinol 60:261-268

31. Glasscock GF, Hein AN, Miller JA, Hintz RL, Rosenfeld RG 1992 Effects of continuous infusion of insulin-like growth factor I and II, alone and in combination with thyroxine or growth hormone, on the neonatal hypophysectomized rat. Endocrinology 130:203-210

32. Moses AC, Nissley SP, Short PA, Rechler MM, Podskalny JM 1980 Purification and characterization of multiplication-stimulating activity. Insulin-like growth factors purified from rat-liver-cell conditioned medium. Eur J Biochem 103:387-400

33. D'Ercole AJ, Underwood LE 1981 Growth factors in fetal growth and development. In: Novy MJ, Resko JA (eds) Fetal Endocrinology. Academic Press. New York, pp 155-182

34. DeChiara TM, Efstratiadis A. Robertson EJ 1990 A growth deficiency phenotype in heterozygous mice carrying an insulin-like growth factor-II gene disrupted by targeting. Nature 345:78-80

35. Rosenfeld R. Thorsson AV, Hintz RL 1979 Increased somatomedin receptor sites in newborn circulating mononuclear cells. J Clin Endocrinol Metab 48:456-461

36. Isaksson OGP, Lindahl A, Nilsson A, Isgaard J 1989 Mechanisms of the stimulatory effect of growth hormone on longitudinal bone growth. Endocr Rev 8:426-438

37. Blum WF, Jenne EW, Reppin F, Kietzmann K, Ranke MB, Bierich JR 1989 Insulin-like growth factor I (IGF-I)-binding protein complex is a better mitogen than free IGF-I. Endocrinology 125:766-772

38. Elgin RG, Busby Jr WH, Clemmons DR 1987 An insulin-like growth factor (IGF) binding protein enhances the biological response to IGF-I. Proc Natl Acad Sci USA 84:3254-3258

39. Maack CA, Lee YR, Spencer EM, Nanney L, Hunt TK, Sommer A 1991 Insulin-like growth factor binding protein-3 potentiates the effects of IGF-1 in rat and pig wound-healing models. Program of the 2 nd International Symposium on Insulin-like Growth Factors/Somatomedins, San Francisco. p 71 (abstr)

40. Shimasaki S, Shimonaka M. Zhang H-P. Ling N 1991 Identification of five different insulin-like growth factor binding proteins (IGFBPs) from adult rat serum and molecular cloning of a novel IGFBP-5 in rat and human. $J$ Biol Chem 266:10646-10653

41. Selden RF, Wagner TE, Blethen S, Yun JS, Rowe ME, Goodman HM 1988 Expression of the human growth hormone variant in cultured fibroblasts and transgenic mice. Proc Natl Acad Sci USA 85:8241-8245

42. Frankenne F, Closset J, Gomez F, Scippo ML, Smal J, Hennen G 1988 The physiology of growth hormones (GHs) in pregnant women and partial characterization of the placental GH variant. J Clin Endocrinol Metab $66: 1171-1180$ 